\title{
Loss of epidermal growth factor receptor expression in oral squamous cell carcinoma is associated with invasiveness and epithelial-mesenchymal transition
}

\author{
IYO KIMURA, HIROKO KITAHARA, KAZUHIRO OOI, KOROKU KATO, NATUYO NOGUCHI, \\ KUNIO YOSHIZAWA, HIROYUKI NAKAMURA and SHUICHI KAWASHIRI \\ Department of Oral and Maxillofacial Surgery, Division of Cancer Medicine, \\ Kanazawa University Graduate School of Medical Science, Kanazawa, Ishikawa 920-8640, Japan
}

Received November 10, 2014; Accepted September 17, 2015

DOI: $10.3892 / \mathrm{ol} .2015 .3833$

\begin{abstract}
Inhibition of epidermal growth factor receptor (EGFR) signaling has emerged as a novel therapeutic strategy for the treatment of oral squamous cell carcinoma (OSCC). The EGFR-directed inhibitor cetuximab is currently the only approved targeted therapy for the treatment of OSCC. EGFR status may affect the patient response to cetuximab treatment. In the present study, via analysis of the immunomarker for EGFR, it was revealed that $58.3 \%$ of the total cases investigated stained positively for EGFR expression, and furthermore, that invasiveness was inversely correlated with EGFR expression. Expression levels of EGFR were quantified, and the correlation between EGFR expression and cetuximab sensitivity was investigated using three varying grades of invasive human OSCC line. EGFR expression in high-grade invasive cells was significantly downregulated compared with that of low-grade invasive cells. There was no significant antiproliferative effect in the high-grade invasive cells treated with various concentrations of cetuximab. The EMT-associated genes, N-cadherin, vimentin and Snail, were upregulated in the high-grade invasive cells. The low-grade invasive cells exhibited characteristics of typical epithelial cells, including the expression of E-cadherin and absence of the expression of $\mathrm{N}$-cadherin, vimentin and Snail. Transforming growth factor- $\beta$ induced low-grade invasive cells to undergo an epithelial-mesenchymal transition (EMT)-associated gene switch, which resulted in low levels of EGFR expression. The results of the present study suggested that loss of EGFR expression in OSCC was associated with EMT, and may have functional implications with regard to tumor invasiveness and the resistance to cetuximab treatment.
\end{abstract}

Correspondence to: Dr Hiroyuki Nakamura, Department of Oral and Maxillofacial Surgery, Division of Cancer Medicine, Kanazawa University Graduate School of Medical Science, 13-1 Takara-machi, Kanazawa, Ishikawa 920-8640, Japan

E-mail: hnak@me.com

Key words: oral squamous cell carcinoma, epidermal growth factor receptor, cetuximab, epithelial-mesenchymal transition, invasiveness

\section{Introduction}

Epidermal growth factor receptor (EGFR/ErbB1/HER1) overexpression is found in the majority of oral squamous cell carcinoma (OSCC) tumors, and associations have been made between increased expression levels and an aggressive phenotype, poor prognosis and resistance to anticancer therapy (1). A number of anti-EGFR antibodies (including cetuximab and panitumumab) and small molecule tyrosine kinase inhibitors (including gefitinib and erlotinib), which target EGFR, have been developed (2). However, only the monoclonal antibody cetuximab $\left(\right.$ Erbitux $\left.^{\circledR}\right)$ is currently approved for the treatment of advanced OSCC (3). Cetuximab therapy has been observed to be effective in the treatment of recurrent and metastatic OSCC, as a first-line treatment in combination with platinum-based chemotherapy (4-7), and as a second-line therapy in patients exhibiting platinum-resistant disease (8-10). In clinical practice, EGFR expression may be evaluated by utilizing a standardized immunohistochemistry (IHC) assay, which is designed to assess cell membrane staining (11). IHC studies have demonstrated EGFR overexpression in $>75 \%$ of the total analyzed OSCC cases, demonstrating values of $73.42 \%$ (12), $87.5 \%$ (13) and $72 \%$ (14). However, the cetuximab response rate is typically not greater than $20 \%$ (15), therefore the role of EGFR expression as a predictor of patient response to EGFR-targeted therapeutic agents remains to be fully elucidated.

The sensitivity of certain tumors to cetuximab may be explained by the presence of mutations in the EGFR tyrosine kinase domain $(16,17)$. However, such mutations are rare in OSCC (18). Thus, there is a requirement to elucidate the mechanisms underlying the differential drug response of cancer cells with wild-type EGFR. This may assist with the identification of patients who may respond and clinically benefit from cetuximab treatment, and furthermore may aid in the development of novel therapeutic strategies, in order to circumvent the de novo or acquired resistance of tumors to cetuximab. Tumor resistance mechanisms to cetuximab may also be targetable, and may thus present a potential opportunity to increase the efficacy of cetuximab therapy. In general, tumors that are frequently therapy-resistant may originate from tumor cells exhibiting an epithelial-mesenchymal 
transition (EMT) phenotype (19). During EMT, epithelial cells lose their characteristic polarity and cell-cell contact, and acquire a more migratory mesenchymal phenotype (20). EMT has additionally been demonstrated to promote stem cell properties. Furthermore, the in vitro sensitivity of head and neck cancer cell lines to anticancer agents has been revealed to be affected by EMT-associated gene expression $(21,22)$.

In the present study, the expression of EGFR in human OSCC tissues and cell lines was evaluated and the association between EGFR expression and clinicopathological features in these tissues and cells was investigated. Furthermore, the OSCC cells and tissues were analyzed with regard to their EMT characteristics, and the OSCC cell lines were also examined for their intrinsic sensitivity to cetuximab treatments.

\section{Materials and methods}

Tissue samples. The present study was approved by the Ethics Committee of the Kanazawa University Graduate School of Medical Science (Kanazawa, Japan) and written informed consent was obtained from each patient. The subjects consisted of 24 patients exhibiting primary OSCC who underwent surgical resection of their tumors at the Department of Oral and Maxillofacial Surgery at Kanazawa University Hospital (Kanazawa, Japan), between 1998 and 2008. The patients ranged from 43-89 years old (mean \pm standard deviation, $64.4 \pm 11.2$ years). The tumor-node-metastasis categories were assigned according to the Union for International Cancer Control system (23). The tumor differentiation grade was determined according to the classification criteria proposed by the World Health Organization (24). The mode of tumor invasion was assessed according to the criteria proposed by Yamamoto et al (25).

$I H C$. Each specimen was fixed in $10 \%$ buffered formalin (Sigma-Aldrich Japan K.K., Tokyo, Japan) and subsequently embedded in paraffin for the preparation of serial sections. Immunohistochemical staining was performed using an EGFR pharmDx $^{\mathrm{TM}}$ kit (K1492; Dako Japan K.K., Tokyo, Japan). The specificity of the staining was confirmed using Universal Negative Control for IS-Series Rabbit Primary Antibodies (cat no. IS600; Dako Japan K.K.) rather than primary antibody as a negative control. The images of 3 separate stained regions were captured under a light microscope at x100 magnification and evaluated based on the number of stained tumor cells, according to the method described by Bernardes et al (26). EGFR expression was evaluated based on the extent of immunolabeling in the tumor cell membranes, and was classified on a 4-point scale as follows: 0 , no labeling or labeling in $<10 \%$ of tumor cells; 1 , weak labeling, homogeneous or patchy, in $>10 \%$ of tumor cells; 2, moderate labeling, homogeneous or patchy, in $>10 \%$ of tumor cells; and 3, intense labeling, homogeneous or patchy, in $>10 \%$ of tumor cells. The initial scores were subsequently grouped into two final groups: Low expression (0 or 1$)$ and high expression (2 or 3 ).

Cell lines. A total of 3 human OSCC cell lines, established from tumor biopsies with varying grades of invasive ability, were used: OSC-20 and OSC-19, low-grade invasive cells, and HOC313, high-grade invasive cells. OSC-20 is a cell line derived from a 58-year-old female exhibiting tongue cancer that metastasized to the cervical lymph nodes (27). OSC-19 was derived from a 61-year-old male exhibiting tongue cancer that metastasized to the cervical lymph nodes (28). HOC313 was derived from a 51-year-old female exhibiting squamous cell carcinoma (involving the mandibular gingiva and oral floor) that metastasized to the cervical lymph nodes (29). Additionally, normal human dermal fibroblasts (NHDFs; cat. no. PCS-201-010), obtained from the American Type Culture Collection (Manassas, VA, USA), served as a control.

Proliferation assay and cetuximab sensitivity. A 3-(4,5-dimethylthiazol-2-yl)-2,5-diphenyltetrazolium bromide (MTT) assay was used in order to investigate the ability of cetuximab to inhibit the proliferation of the 3 OSCC lines (OSC-19, OSC-20 and HOC313) in vitro. Initially, 2,500 cells/well were cultured in Dulbecco's modified Eagle's medium (DMEM; D7440; Sigma-Aldrich Japan K.K.) supplemented with Hyclone ${ }^{\mathrm{TM}} 10 \%$ fetal bovine serum (FBS; GE Healthcare, Logan, UT, USA), in 96 -well tissue culture plates. Following $24 \mathrm{~h}$ of culture, the cells were treated with varying concentrations of cetuximab (Erbitux ${ }^{\circledast}$; Merck Serono Co., Ltd., Tokyo, Japan; 0, 0.005 and $0.01 \mu \mathrm{g} / \mathrm{ml}$ ) diluted in DMEM supplemented with $2 \%$ FBS. In order to measure the number of metabolically active cells following 24, 48 and $72 \mathrm{~h}$ of incubation, an MTT assay was performed and the results were quantified according to the manufacturer's protocols. The optical density at $450 \mathrm{~nm}$ was measured using a microplate reader (iMark Microplate Absorbance Reader; Bio-Rad Laboratories, Inc., Hercules, CA, USA).

RNA extraction, complementary DNA (cDNA) synthesis and quantitative polymerase chain reaction ( $q P C R$ ). The messenger RNA (mRNA) levels of EGFR, E-cadherin, vimentin, Twist and Snail were analyzed using a Rotor-Gene Q 2plex HRM System (9001560; Qiagen GmbH, Hilden, Germany) with FAM/ZEN/IBFQ probes (DNA sequence unopened; Integrated DNA Technologies, Inc., Coralville, IA, USA). Total RNA was extracted using the RNeasy Protect Mini kit (74124; Qiagen $\mathrm{GmbH}$ ), and cDNA was obtained by utilizing the PrimeScript 1st Strand cDNA Synthesis kit (6110A; Takara Bio, Inc., Otsu, Japan). All reactions and conditions were performed according to the manufacturer's protocols. Ribosomal RNA (18S) was amplified as an internal standard using HEX/ZEN/IBFQ probes (DNA sequence unopened; Integrated DNA Technologies, Inc.). Data were analyzed using the comparative $\mathrm{Cq}$ method, which presented the data as a fold-change in expression level relative to a calibrator sample (in the present case, the mean expression of the 3 replicates of the NHDF cell line).

Enzyme-linked immunosorbent assay (ELISA). For enzyme-linked immunosorbent assay analysis of EGFR and phosphorylated EGFR, 3 human oral cancer cell lines (OSC-20, OSC-19 and HOC313) were cultured. Following incubation for $24 \mathrm{~h}$, the cells were seeded into a 96-well tissue culture plate (BD Biosciences, Tokyo, Japan) and fixed for $5 \mathrm{~min}$ by $4 \%$ formaldehyde solution (Sigma-Aldrich Japan K.K.) in phosphate-buffered saline (Sigma-Aldrich Japan K.K.). The expression levels of EGFR and phosphorylated EGFR were quantified using the human EGFR In-Cell ELISA kit (ab126419; 
Table I. Correlation between EGFR expression and clinicopathological features of oral squamous cell carcinoma patients.

\begin{tabular}{|c|c|c|c|}
\hline \multirow[b]{2}{*}{ Clinicopathological feature } & \multicolumn{2}{|c|}{ EGFR expression } & \multirow[b]{2}{*}{ P-value } \\
\hline & High $(n=14)$ & Low $(n=10)$ & \\
\hline Tumor category & & & 0.991 \\
\hline $\mathrm{T} 1$ & 3 & 2 & \\
\hline $\mathrm{T} 2$ & 8 & 6 & \\
\hline $\mathrm{T} 3$ & 1 & 0 & \\
\hline $\mathrm{T} 4$ & 2 & 2 & \\
\hline Node category & & & 0.456 \\
\hline Negative & 13 & 7 & \\
\hline Positive & 1 & 3 & \\
\hline Local recurrence & & & 0.071 \\
\hline Negative & 10 & 4 & \\
\hline Positive & 4 & 6 & \\
\hline Differentiation & & & 0.137 \\
\hline Well & 10 & 7 & \\
\hline Moderate & 3 & 0 & \\
\hline Poor & 1 & 3 & \\
\hline Mode of invasion, grade & & & $0.039^{\mathrm{a}}$ \\
\hline 3 & 7 & 1 & \\
\hline $4 \mathrm{C}$ & 5 & 3 & \\
\hline $4 \mathrm{D}$ & 2 & 6 & \\
\hline
\end{tabular}

${ }^{\mathrm{a}} \mathrm{P}<0.05$. EGFR, epidermal growth factor receptor.

Abcam, Cambridge, MA, USA) according to the manufacturer's protocols. The data were presented as a fold-change in expression level relative to the mean expression of the 3 replicates of the NHDF cell line.

EMT induction. In order to induce EMT, OSC-20 and OSC-19 cells were seeded at $70 \%$ confluence into a $10-\mathrm{cm}$ plastic dish (BD Biosciences) and cultured for 48 and $72 \mathrm{~h}$ in DMEM to induce EMT (Sigma-Aldrich Japan K.K.)with 0.5\% FBS. Recombinant human transforming growth factor- $\beta 1$ (240-B; R\&D Systems, Inc., Minneapolis, MN, USA) was added at a final concentration of $5 \mathrm{ng} / \mathrm{ml}$.

Statistical analysis. Statistical analysis was performed using $\mathrm{JMP}^{\circledR}$ version 9.0 (SAS Institute, Inc., Cary, NC, USA). The association between EGFR protein expression and clinicopathological features was examined using Pearson's $\chi^{2}$ test. Data from the ELISA and MTT assays are presented as the mean \pm standard error. Differences between groups were tested for statistical significance using the two-tailed Mann-Whitney U test. $\mathrm{P}<0.05$ was considered to indicate a statistically significant difference.

\section{Results}

EGFR expression is associated with certain clinicopathological features. EGFR expression was detected in the cell membrane and cytoplasm of the tumor cells (Fig. 1). According to the criteria for EGFR immunohistochemical evaluation (26), 58.3\%
(14/24) of the total cases investigated were positive for EGFR expression. Table I illustrates the correlations between EGFR expression and certain clinicopathological features. EGFR expression in high-grade invasive OSCC (mode of invasion, grade 4D) was significantly downregulated compared with that of low-grade invasive OSCC (mode of invasion, grades 3 and 4C; $\mathrm{P}=0.039)$. By contrast, EGFR expression did not correlate with tumor size $(\mathrm{P}=0.991)$, local recurrence $(\mathrm{P}=0.071)$ histological differentiation $(\mathrm{P}=0.137)$ or lymph node metastasis $(\mathrm{P}=0.456)$.

EGFR is differentially expressed in the 3 different grades of invasive OSCC cell lines. As demonstrated by immunohistochemical analysis, only invasiveness (mode of invasion) was inversely correlated with the expression of EGFR (Table I). Therefore, EGFR expression in the 3 different grades of invasive human OSCC lines (OSC-19, OSC-20 and HOC313) was analyzed at the mRNA and protein level using qPCR and ELISA, respectively. Data are presented as a fold-change relative to the mean of 3 replicates of the NHDF cell line (Fig. 2). Among the three OSCC cell lines (OSC-19, OSC-20 and HOC313), the EGFR mRNA expression level ranged from 0.7- to 3.7-fold higher compared with that of the NHDFs (Fig. 2A). The expression of EGFR mRNA in the 2 low-grade invasive cell lines (OSC-20 and OSC-19) was 3.7- and 2.3-fold higher compared with the NHDFs, respectively. The EGFR mRNA expression in the high-grade invasive cells (HOC313) was markedly reduced and similar to that of the NHDFs. By contrast, the 2 low-grade invasive cell lines (OSC-20 and OSC-19) possessed EGFR 
$\mathbf{A}$

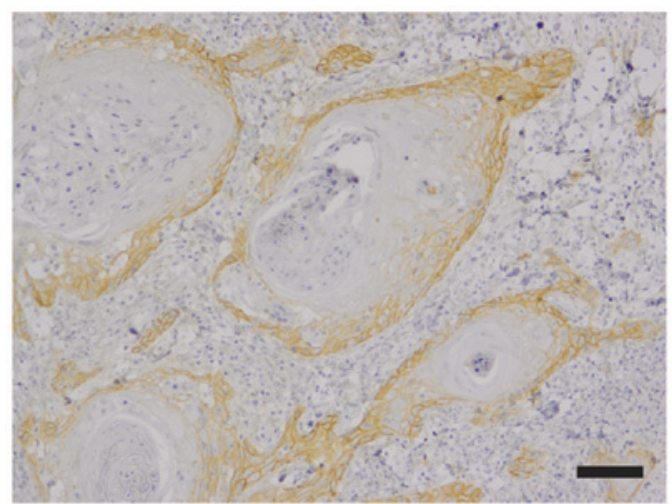

B

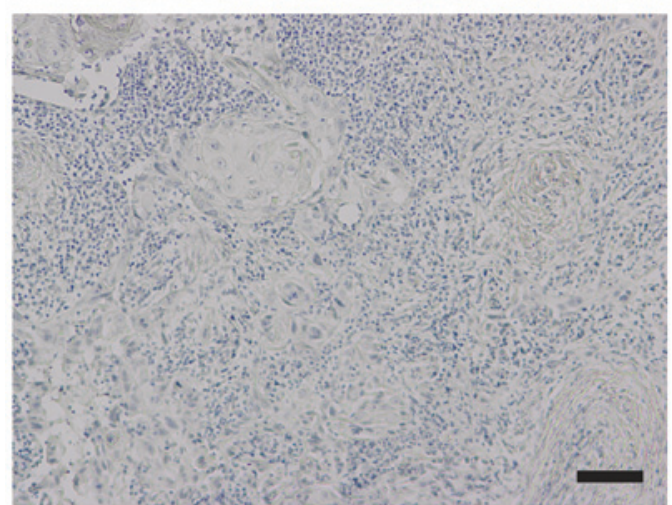

Figure 1. Immunohistochemical staining of EGFR in human OSCC tissues. (A) Positive immunoexpression of EGFR in OSCC. (B) Specificity of the staining was confirmed by using non-immune antibody instead of primary antibody as a negative control. Scale bar, $100 \mu \mathrm{m}$. EGFR, epidermal growth factor receptor; OSCC, oral squamous cell carcinoma.

protein expression levels 3.5- and 2.1-fold higher compared with those of the NHDFs, respectively (Fig. 2B). The high-grade invasive cells (HOC313) exhibited the lowest levels of EGFR protein expression. The quantities of phosphorylated EGFR were assessed in order to determine the activation status of EGFR. Expression levels of phosphorylated EGFR ranged from 2.2- to 0.87 -fold higher compared with those of the NHDFs (Fig. 2C). Expression patterns of phosphorylated EGFR were similar to the expression patterns of EGFR mRNA and protein.

Cetuximab sensitivity is dependent on OSCC invasiveness. In order to evaluate the significance of EGFR status in relation to cetuximab sensitivity, the cetuximab sensitivity of 3 human OSCC lines exhibiting varying grades of invasive ability (OSC-19, OSC-20 and HOC313) was evaluated. Cells were seeded at clonal density, and the antiproliferative effects of cetuximab were determined using an MTT assay (Fig. 3). Antiproliferative effects of cetuximab were observed in the OSC-20 and OSC-19 cell lines. In the OSC-20 and OSC-19 cells (low-grade invasive OSCC), following incubation with cetuximab $(0.005 \mu \mathrm{g} / \mathrm{ml}$ and $0.01 \mu \mathrm{g} / \mathrm{ml})$ for 48 and $72 \mathrm{~h}$, proliferation was significantly inhibited compared with non-treated cells $(\mathrm{P}<0.05)$. However, the varying concentrations of cetuximab exerted no significant antiproliferative effects on the HOC 313 cell line $(\mathrm{P}>0.05)$.

An EMT phenotype is detectable in the high-grade invasive OSCC cell line. In order to evaluate whether EGFR expression was associated with the features of EMT, levels
A

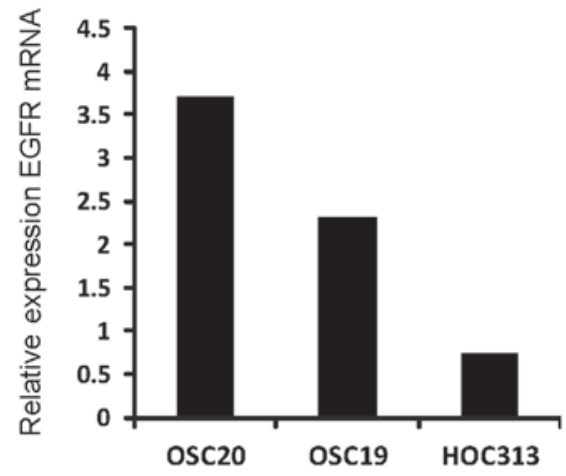

B

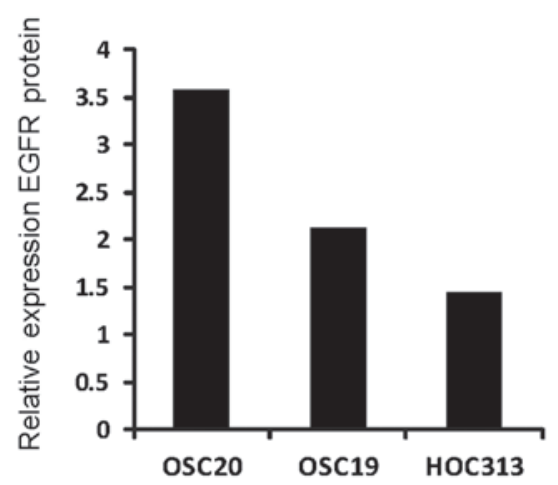

C

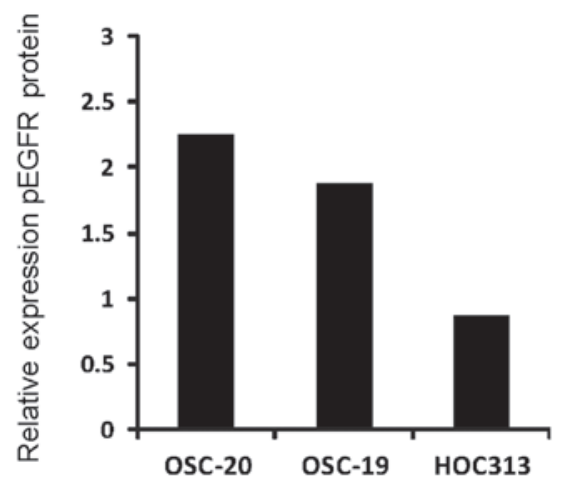

Figure 2. EGFR expression in 3 varying grades of invasive human oral squamous cell carcinoma line. The OSC-19, OSC-20 and HOC313 cell lines were evaluated for variations in (A) EGFR mRNA, (B) EGFR protein and (C) pEGFR expression levels. Data are presented as a fold difference in expression level relative to the mean expression of the normal human dermal fibroblast cells. EGFR, epidermal growth factor receptor; p, phosphorylated; mRNA, messenger RNA.

of N-cadherin, E-cadherin, vimentin and Snail were investigated in 3 different invasive human OSCC cell lines (OSC-19, OSC-20 and HOC313; Fig. 4A). The expression levels of EMT-associated genes in the OSC-19 and HOC313 cells are presented as fold-changes relative to the OSC-20 cells. The HOC 313 cells (high-grade invasive cells with loss of EGFR expression) exhibited a mesenchymal phenotype manifested through loss of E-cadherin and acquisition of $\mathrm{N}$-cadherin, vimentin and Snail expression compared with the OSC-20 and OSC-19 cell lines (Fig. 4A). In order to examine whether TGF- $\beta$ altered the expression of the EMT-associated genes and EGFR, the 2 low-grade invasive cell lines (OSC-20 and OSC-19) were exposed to TGF- $\beta$ (Fig. 4B). Expression levels are presented as fold differences relative to the control vehicle at 48 and $72 \mathrm{~h}$, respectively. Serial examination of EMT 
A

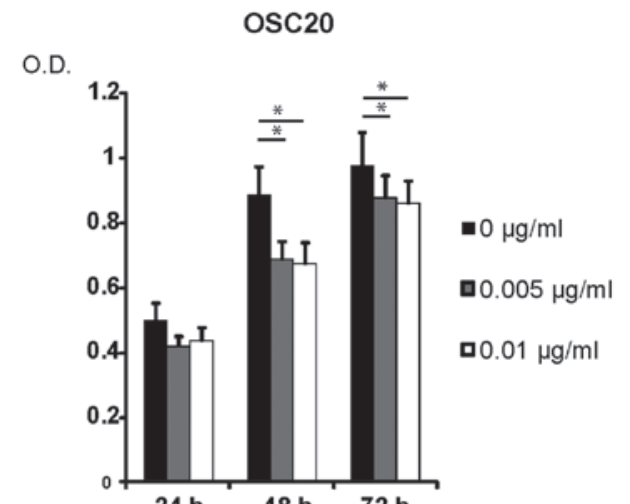

B

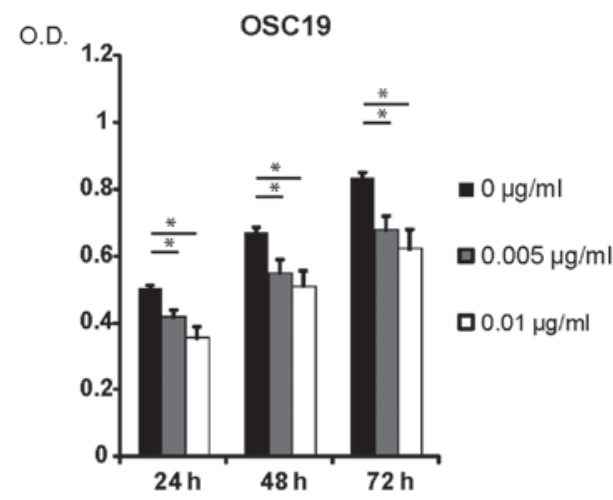

C

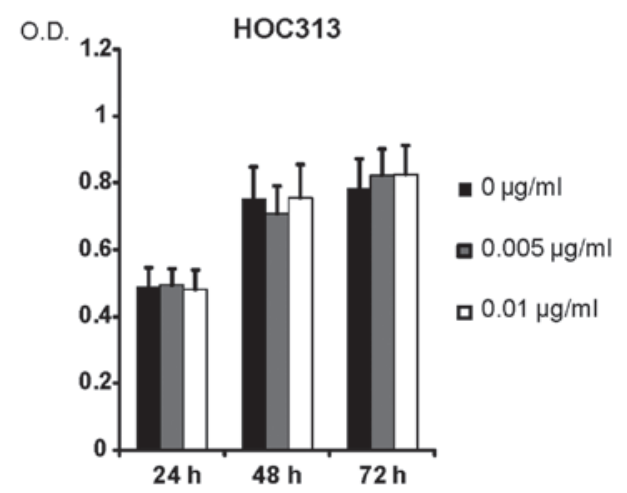

Figure 3. Cetuximab sensitivity of 3 varying grades of invasive human oral squamous cell carcinoma line. (A) OSC-20, (B) OSC-19 and (C) HOC313 cells were treated with various concentrations of cetuximab as indicated, and the antiproliferative effects of cetuximab treatment were determined by 3-(4, 5-dimethylthiazol-2-yl)-2,5-diphenyltetrazolium bromide assay. Each data point represents the mean of three independent experiments. Data are presented as standard deviations. Error bars correspond to the standard error. ${ }^{*} \mathrm{P}<0.05$. O.D., optical density.

markers (loss of E-cadherin and upregulation of N-cadherin, vimentin and Snail) over a specific time course (48 and $72 \mathrm{~h}$ ) revealed that TGF- $\beta$ treatment induced EMT in the OSC-20 cells (Fig. 4B). By contrast, TGF- $\beta$ was not effective in the induction of EMT in the OSC-19 cells. Notably, total EGFR mRNA in the OSC-20 and OSC-19 cells was reduced following EMT induction by TGF- $\beta$ treatment.

\section{Discussion}

EGFR (a tyrosine kinase receptor from the ErbB family) is an oncogene that has been identified in a number of malignancies, including cancer of the breast, prostate, pulmonary system,
A

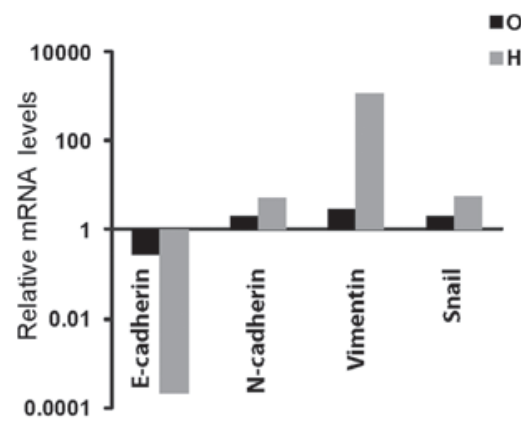

B

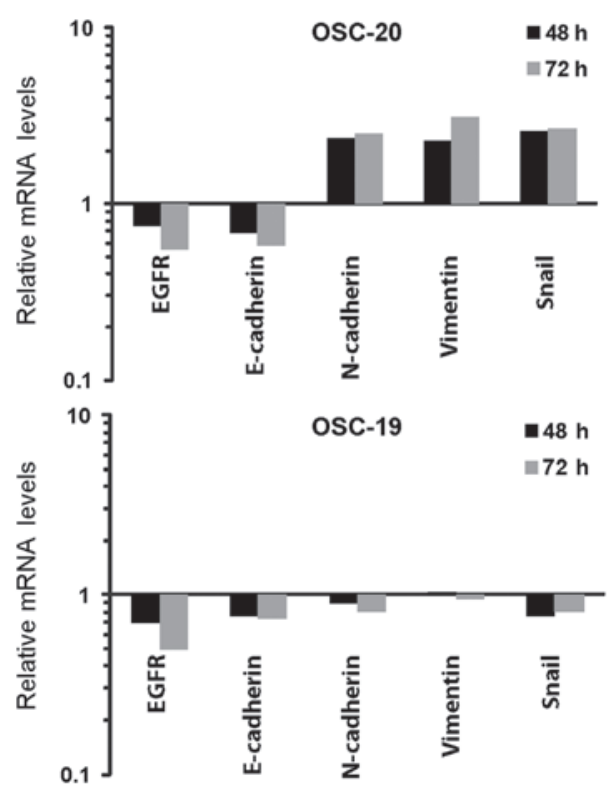

Figure 4. EGFR and EMT-associated gene expression in 3 varying grades of invasive human OSCC line. (A) Relative mRNA expression levels of EMT-associated genes, E-cadherin, N-cadherin, vimentin and Snail, in OSC-20, OSC-19 and HOC313 cell lines. The high-grade invasive OSCC cell line (HOC313) demonstrated upregulation of EMT-associated genes. Expression levels in OSC-19 and HOC313 are displayed as fold-changes relative to the expression levels in OSC-20. (B) Relative mRNA expression levels of EGFR and EMT-associated genes, E-cadherin, N-cadherin, vimentin and Snail, in OSC-20 and OSC-19 cell lines. TGF- $\beta$ induced EMT-associated gene expression in low-grade invasive OSCC cell lines (OSC-20 and OSC-19). The cells were treated with human TGF- $\beta$ or a control vehicle for 48 and $72 \mathrm{~h}$. Expression levels are displayed as fold-changes relative to the control vehicle at 48 and $72 \mathrm{~h}$, respectively. EGFR, epidermal growth factor receptor; EMT, epithelial-mesenchymal transition; OSCC, oral squamous cell carcinoma; mRNA, messenger RNA; TGF- $\beta$, transforming growth factor $\beta$.

bladder, and head and neck (30). EGFR is overexpressed and appears to be the dominant controlling factor underlying the malignant phenotype in head and neck squamous cell carcinomas, via adjustment of the molecules involved in invasive angiogenic and lymphangiogenic processes (12). By analyzing the immunomarker for EGFR in the present study, positive staining for EGFR expression was identified in $58.3 \%$ of the total cases analyzed. The results of the present study were consistent with previously reported data (12-14). Furthermore, to the best of our knowledge, the present study demonstrated for the first time that invasiveness (mode of invasion) was inversely correlated with EGFR expression in OSCC patients. The present study also revealed that there 
is a loss of EGFR expression in the high-grade invasive OSCC line (HOC313 cells). The results of the present study suggested that loss of EGFR expression was associated with acquirement of an invasive phenotype in OSCC. This potential association will require further investigation in future studies.

The present study analyzed the correlation between EGFR expression and the sensitivity to cetuximab using 3 human OSCC cell lines (OSC-19, OSC-20 and HOC313), possessing varying grades of invasive abilities. Variability in the responses of certain cell lines to cetuximab treatment was identified. Cetuximab was observed to suppress cell growth by $\sim 23 \%$ in the most treatment-sensitive cell line (OSC-20), however, it exerted no effect on the HOC 313 cell line. The OSC-20 cell line demonstrated a marked increase in EGFR mRNA and protein levels compared with the HOC 313 cell line. However, the HOC 313 cell line, which was unaffected by cetuximab treatment, demonstrated the lowest levels of EGFR expression. When evaluating the affect of EGFR expression on the cetuximab treatment responses, a significant difference in EGFR expression levels was observed between cetuximab-sensitive (OSC-20) and -resistant cells (HOC313). Cetuximab-resistant cell lines exhibited reduced levels of EGFR expression, indicating that the cetuximab treatment response may be dependent on EGFR expression status. In addition, increased levels of phosphorylated EGFR correlated with cetuximab sensitivity, revealing a potential role of activated EGFR in patient responses to cetuximab. A previous study has suggested that cells may be sensitive to the inhibition of EGFR only if they are dependent on EGFR activation for cell survival and growth (31). In agreement with these previous results, the levels of phosphorylated EGFR have been utilized to predict gefitinib (an EGFR tyrosine kinase inhibitor) sensitivity in OSCC patients (32).

The response to EGFR-targeted agents is inversely correlated with EMT in multiple tumor types without known EGFR mutations, including non-small cell lung cancer, and carcinoma of the bladder, colorectal region, pancreas and breast (33-37). In the present study, the EMT-associated genes, N-cadherin, vimentin and Snail, were upregulated in cetuximab-resistant OSCC tumor cells (HOC313). The present study additionally demonstrated that TGF- $\beta$ was able to induce a low-grade invasive OSCC cell line (OSC-20) to undergo an EMT-associated gene switch, which resulted in a loss of EGFR expression. The results of the present study indicated that the net effect of TGF- $\beta$ signaling was the loss of EGFR activity, accompanied by a concomitant EMT-associated gene switch of tumor cells, as well as acquirement of a migratory mesenchymal phenotype. Further studies are required in order to elucidate the precise molecular mechanisms underlying the association between EMT and the regulation of EGFR expression.

In the present study, it was demonstrated that EGFR status affected the response to cetuximab treatments, therefore, the level of invasiveness or presence of an EMT phenotype may potentially assist in the prediction of EGFR status. EMT-associated alterations in gene expression, including the upregulation of $\mathrm{N}$-cadherin, vimentin and Snail, have additionally been proposed as potential biomarkers for the indication of EGFR status and the prediction of patient response to cetuximab treatment. However, further in vivo studies using clinical samples are required in order to confirm these results.

\section{Acknowledgements}

The authors would like to thank American Journal Experts for providing English language editing.

\section{References}

1. Ang KK, Berkey BA, Tu X, Zhang HZ, Katz R, Hammond EH, $\mathrm{Fu}$ KK and Milas L: Impact of epidermal growth factor receptor expression on survival and pattern of relapse in patients with advanced head and neck carcinoma. Cancer Res 62: 7350-7356, 2002.

2. Mahipal A, Kothari N and Gupta S: Epidermal growth factor receptor inhibitors: coming of age. Cancer Control 21: 74-79, 2014

3. Loeffler-Ragg J, Schwentner I, Sprinzl GM and Zwierzina H: EGFR inhibition as a therapy for head and neck squamous cell carcinoma. Expert Opin Investig Drugs 17: 1517-1531, 2008.

4. Bourhis J, Rivera F, Mesia R, Awada A, Geoffrois L, Borel C, Humblet Y, Lopez-Pousa A, Hitt R, Vega Villegas ME, et al: Phase I/II study of cetuximab in combination with cisplatin or carboplatin and fluorouracil in patients with recurrent or metastatic squamous cell carcinoma of the head and neck. J Clin Oncol 24: 2866-2872, 2006.

5. Burtness B, Goldwasser MA, Flood W, Mattar B and Forastiere AA; Eastern Cooperative Oncology Group: Phase III randomized trial of cisplatin plus placebo compared with cisplatin plus cetuximab in metastatic/recurrent head and neck cancer: An eastern cooperative oncology group study. J Clin Oncol 23: 8646-8654, 2005.

6. Shin DM, Donato NJ, Perez-Soler R, Shin HJ, Wu JY, Zhang P, Lawhorn K, Khuri FR, Glisson BS, Myers J, et al: Epidermal growth factor receptor-targeted therapy with $\mathrm{C} 225$ and cisplatin in patients with head and neck cancer. Clin Cancer Res 7: 1204-1213, 2001

7. Vermorken JB, Mesia R, Rivera F, Remenar E, Kawecki A, Rottey S, Erfan J, Zabolotnyy D, Kienzer HR and Cupissol D, et al: Platinum-based chemotherapy plus cetuximab in head and neck cancer. N Engl J Med 359: 1116-1127, 2008.

8. Baselga J, Trigo JM, Bourhis J, et al: Phase II multicenter study of the antiepidermal growth factor receptor monoclonal antibody cetuximab in combination with platinum-based chemotherapy in patients with platinum-refractory metastatic and/or recurrent squamous cell carcinoma of the head and neck. J Clin Oncol 23: 5568-5577, 2005.

9. Herbst RS, Arquette M, Shin DM, et al: Phase II multicenter study of the epidermal growth factor receptor antibody cetuximab and cisplatin for recurrent and refractory squamous cell carcinoma of the head and neck. J Clin Oncol 23: 5578-5587, 2005.

10. Vermorken JB, Trigo J, Hitt R, et al: Open-label, uncontrolled, multicenter phase II study to evaluate the efficacy and toxicity of cetuximab as a single agent in patients with recurrent and/or metastatic squamous cell carcinoma of the head and neck who failed to respond to platinum-based therapy. J Clin Oncol 25: 2171-2177, 2007.

11. O-charoenrat P, Rhys-Evans PH, Archer DJ and Eccles SA: C-erbB receptors in squamous cell carcinomas of the head and neck: Clinical significance and correlation with matrix metalloproteinases and vascular endothelial growth factors. Oral Oncol 38: 73-80, 2002.

12. O-charoenrat P, Rhys-Evans PH, Modjtahedi $\mathrm{H}$ and Eccles SA: The role of c-erbB receptors and ligands in head and neck squamous cell carcinoma. Oral Oncol 38: 627-640, 2002.

13. Sarkis SA, Abdullah BH, Abdul Majeed BA and Talabani NG: Immunohistochemical expression of epidermal growth factor receptor (EGFR) in oral squamous cell carcinoma in relation to proliferation, apoptosis, angiogenesis and lymphangiogenesis. Head Neck Oncol 2: 13, 2010.

14. Ryott M, Wangsa D, Heselmeyer-Haddad K, Lindholm J, Elmberger G, Auer G, Avall Lundqvist E, Ried T and Munck-Wikland E: EGFR protein overexpression and gene copy number increases in oral tongue squamous cell carcinoma. Eur J Cancer 45: 1700-1708, 2009. 
15. Bonner JA, Harari PM, Giralt J, Azarnia N, Shin DM, Cohen RB, Jones CU, Sur R, Raben D, Jassem J, et al: Radiotherapy plus cetuximab for squamous-cell carcinoma of the head and neck. N Engl J Med 354: 567-578, 2006.

16. Lynch TJ, Bell DW, Sordella R, Gurubhagavatula S, Okimoto RA, Brannigan BW, Harris PL, Haserlat SM, Supko JG, Haluska FG, et al: Activating mutations in the epidermal growth factor receptor underlying responsiveness of non-small-cell lung cancer to gefitinib. N Engl J Med 350: 2129-2139, 2004.

17. Paez JG, Jänne PA, Lee JC, Tracy S, Greulich H, Gabriel S, Herman P, Kaye FJ, Lindeman N, Boggon TJ, et al: EGFR mutations in lung cancer: Correlation with clinical response to gefitinib therapy. Science 304: 1497-1500, 2004

18. Lemos-González Y, Páez de la Cadena M, Rodríguez-Berrocal FJ, Rodríguez-Piñeiro AM, Pallas E and Valverde D: Absence of activating mutations in the EGFR kinase domain in Spanish head and neck cancer patients. Tumour Biol 28: 273-279, 2007.

19. Nantajit D, Lin D and Li JJ: The network of epithelial-mesenchymal transition: Potential new targets for tumor resistance. J Cancer Res Clin Oncol 141: 1697-1713, 2015.

20. Banyard J and Bielenberg DR: The role of EMT and MET in cancer dissemination. Connect Tissue Res: 1-11, 2015.

21. Hsu DS, Lan HY, Huang CH, Tai SK, Chang SY, Tsai TL, Chang CC, Tzeng CH, Wu KJ, Kao JY and Yang MH: Regulation of excision repair cross-complementation group 1 by Snail contributes to cisplatin resistance in head and neck cancer. Clin Cancer Res 16: 4561-4571, 2010

22. Skvortsova I, Skvortsov S, Raju U, Stasyk T, Riesterer O, Schottdorf EM, Popper BA, Schiestl B, Eichberger P, Debbage P, et al: Epithelial-to-mesenchymal transition and c-myc expression are the determinants of cetuximab-induced enhancement of squamous cell carcinoma radioresponse. Radiother Oncol 96 : $108-115,2010$.

23. Greene FL and Sobin LH: A worldwide approach to the TNM staging system: collaborative efforts of the AJCC and UICC. J Surg Oncol 99: 269-272, 2009.

24. Thompson L: World Health Organization classification of tumours: pathology and genetics of head and neck tumours. Ear Nose Throat J 85: 74, 2006.

25. Yamamoto E, Kohama G, Sunakawa H, Iwai M and Hiratsuka $H$ : Mode of invasion, bleomycin sensitivity and clinical course in squamous cell carcinoma of the oral cavity. Cancer 51 : 2175-2180, 1983

26. Bernardes VF, Gleber-Netto FO, Sousa SF, Silva TA and Aguiar MC: Clinical significance of EGFR, Her-2 and EGF in oral squamous cell carcinoma: A case control study. J Exp Clin Cancer Res 29: 40, 2010

27. Yokoi T, Hirata S, Nishimura F, Miyakawa A, Odajima T and Kohama G: Some properties of a newly established human cell line derived from an oral squamous carcinoma. Tumor Res 25 : 93-103, 1990.
28. Yokoi T, Homma $\mathrm{H}$ and Odajima T: Establishment and characterization of OSC-19 cell line in serum- and protein-free culture. Tumor Res 24: 1-17, 1988.

29. Ishisaki A, Oida S, Momose F, Amagasa T, Rikimaru K, Ichijo $\mathrm{H}$ and Sasaki $\mathrm{S}$ : Identification and characterization of autocrine-motility-factor-like activity in oral squamous-cell-carcinoma cells. Int J Cancer 59: 783-788, 1994.

30. Oliveira S, van Bergen en Henegouwen PM, Storm G and Schiffelers RM: Molecular biology of epidermal growth factor receptor inhibition for cancer therapy. Expert Opin Biol Ther 6: 605-617, 2006.

31. Pernas FG, Allen CT, Winters ME, Yan B, Friedman J, Dabir B, Saigal K, Mundinger GS, Xu X, Morris JC, et al: Proteomic signatures of epidermal growth factor receptor and survival signal pathways correspond to gefitinib sensitivity in head and neck cancer. Clin Cancer Res 15: 2361-2372, 2009.

32. Hamakawa H, Nakashiro K, Sumida T, Shintani S, Myers JN, Takes RP, Rinaldo A and Ferlito A: Basic evidence of molecular targeted therapy for oral cancer and salivary gland cancer. Head Neck 30: 800-809, 2008.

33. Yauch RL, Januario T, Eberhard DA, Cavet G, Zhu W, Fu L, Pham TQ, Soriano R, Stinson J, Seshagiri S, et al: Epithelial versus mesenchymal phenotype determines in vitro sensitivity and predicts clinical activity of erlotinib in lung cancer patients. Clin Cancer Res 11: 8686-8698, 2005.

34. Thomson S, Petti F, Sujka-Kwok I, Epstein D and Haley JD: Kinase switching in mesenchymal-like non-small cell lung cancer lines contributes to EGFR inhibitor resistance through pathway redundancy. Clin Exp Metastasis 25: 843-854, 2008.

35. Thomson S, Buck E, Petti F, Griffin G, Brown E, Ramnarine N, Iwata KK, Gibson N and Haley JD: Epithelial to mesenchymal transition is a determinant of sensitivity of non-small-cell lung carcinoma cell lines and xenografts to epidermal growth factor receptor inhibition. Cancer Res 65: 9455-9462, 2005.

36. Adam L, Zhong M, Choi W, Qi W, Nicoloso M, Arora A, Calin G, Wang H, Siefker-Radtke A, McConkey D, et al: miR-200 expression regulates epithelial-to-mesenchymal transition in bladder cancer cells and reverses resistance to epidermal growth factor receptor therapy. Clin Cancer Res 15: 5060-5072, 2009

37. Barr S, Thomson S, Buck E, Russo S, Petti F, Sujka-Kwok I, Eyzaguirre A, Rosenfeld-Franklin M, Gibson NW, Miglarese M, et al: Bypassing cellular EGF receptor dependence through epithelial-to-mesenchymal-like transitions. Clin Exp Metastasis 25: 685-693, 2008. 